\title{
Double Autologous Stem Cell Transplantation in a Case of Non- secretory Multiple Myeloma
}

\author{
Erzsébet Lázár¹, Marius Găzdac², Szende Jakab¹, István Benedek Jr¹, Judit-Beáta Köpeczi², \\ Annamária Pakucs² , János Ács³ ${ }^{3}$ István Benedek \\ 1 University of Medicine and Pharmacy, Tîrgu Mureș, Romania \\ 2 Clinic of Hematology and Bone Marrow Transplantation Unit, Tîrgu Mureş, Romania \\ 3 Clinic of Neurosurgery, Tîrgu Mureş, Romania
}

\section{CORRESPONDENCE}

\section{Szende Jakab}

Str. Revolutiei nr. 35

540042 Tîrgu Mures, Romania

Tel: +40 265218739

E-mail: szende_jakab@yahoo.ro

\section{ARTICLE HISTORY}

Received: 2 November, 2016

Accepted: 10 November, 2016
Erzsébet Lázár • Str. Gheorghe Marinescu nr. 38 540139 Tîrgu Mures, Romania. Tel: +40 265215551 Marius Găzdac • Str. Revoluției nr. 35, 540042 Tîrgu Mureș, Romania. Tel: +40 265218739

István Benedek Jr • Str. Gheorghe Marinescu nr. 38, 540139 Tîrgu Mureș, Romania. Tel: +40 265215551 Judit-Beáta Köpeczi • Str. Revolutiei nr. 35, 540042 Tîrgu Mureș, Romania. Tel: +40 265218739 Annamária Pakucs • Str. Revolutiei nr. 35, 540042 Tîrgu Mureș, Romania. Tel: +40 265218739 János Ács • Str. Gheorghe Marinescu nr. 50, 540139 Tîrgu Mureș, Romania. Tel: +40 265212111

István Benedek • Str. Gheorghe Marinescu nr. 38 , 540139 Tîrgu Mures, Romania. Tel: +40 265215551

\section{ABSTRACT}

Multiple myeloma represents a challenge for hematologists because it has become more frequent at a young age in recent years. This is why autologous stem cell transplantation is included in the standard treatment of myeloma patients. We present the case of a 39-year-old patient who was diagnosed with non-secretory myeloma with double autologous transplantation and underwent neurosurgery for spinal cord compression caused by a plasmocytoma at D5 level. We present the evolution and complexity of this very difficult case.

Keywords: multiple myeloma, plasmocitoma, autologous transplantation

\section{INTRODUCTION}

It has been shown that the introduction of autologous stem cell transplantation in the standard treatment of multiple myeloma has led to an improvement in the patients' evolution and quality of life. ${ }^{1,2}$

Myeloma is currently the only disorder that can be treated with double autologous transplantation. This is the reason why, in this disease, stem cell mobilization and harvesting needs to be perfomed as soon as possible after the positive diagnosis. Mobilization of the proper quantity of CD34+ stem cells is almost impossible after several chemotherapy courses. In order to perform a successful autologous stem cell transplant in multiple myeloma, the necessary quantity of cells is $2.6 \times 10^{6}$ cells $/ \mathrm{kg}$ for one procedure; therefore we need, in ideal cases, at least a double amount of the mentioned number of cells. ${ }^{3}$

The treatment of myeloma requires a multidisciplinary approach because in many cases patients may need neurosurgical treatment and/or radiotherapy due to compressive complications at the level of the vertebrae. 


\section{CASE REPORT}

We present a very complex case of a young 39-year-old male patient who was diagnosed with non-secretory multiple myeloma. At the time of hospital admission, he presented fatigue and very strong diffuse bone pain.

The laboratory results showed moderate secondary normochromic, normocytic anemia, and the cellularity of the bone marrow was moderately reduced with the presence of $>45 \%$ abnormal plasmocytes.

The flow-cytometric examination confirmed that there was a CD138+ infiltration of the bone marrow.

Due to the non-secretory type of the disease, the immunoglobulin level was not relevant. The radiological examination of the skull (Figure 1), vertebrae and ribs showed multiple osteolytic lesions.

The MRI examination of the thoracic spine showed an expansive tumoral infiltration of the sternum, associated with osteolytic lesions at the costovertebral level.

The patient received 3 courses of VAD (Vincristin, Adriablastin, Dexamethason) chemotherapy plus bone remineralization treatment with zoledronic acid, followed by hematopoietic stem cell mobilization and harvesting. The harvesting was successful, and we obtained a quantity of $7.9 \times 10^{6}$ cells $/ \mathrm{kg}$ by mobilization with granulocytestimulating factor (G-CSF $10 \mu \mathrm{g} / \mathrm{kg}$ ).

Due to the young age of the patient after mobilization, we continued the chemotherapy courses with VAD plus Melphalan in order to reduce the biological activity of the disease. Following this treatment, a bone scintigraphy was performed, which showed the persistence of the bone lesions. In order to stabilize the patient, the autologous transplantation was performed at our clinic in June 2015. The conditioning treatment was a standard high dose (HD) of Melphalan $200 \mathrm{mg} / \mathrm{m}^{2} .^{4}$ The autologous transplant was well tolerated with minimal infectious complication.

After a period of 2 months free of treatment, we continued with 4 courses of polichemotherapy and biphosphonate therapy.

The evolution was positive, however at 1 year after the first transplant the symptoms of spinal cord compression and bone pain reoccurred at the level of the dorsal vertebrae. The emergency MRI showed the presence of a tumoral mass at the level of the D5 vertebra, and the patient needed decompression laminectomy, which was performed at the Clinic of Neurosurgery of the County Emergency Clinical Hospital of Tîrgu Mureș. The histological examination confirmed the diagnosis of extramedullary plasmocitoma.

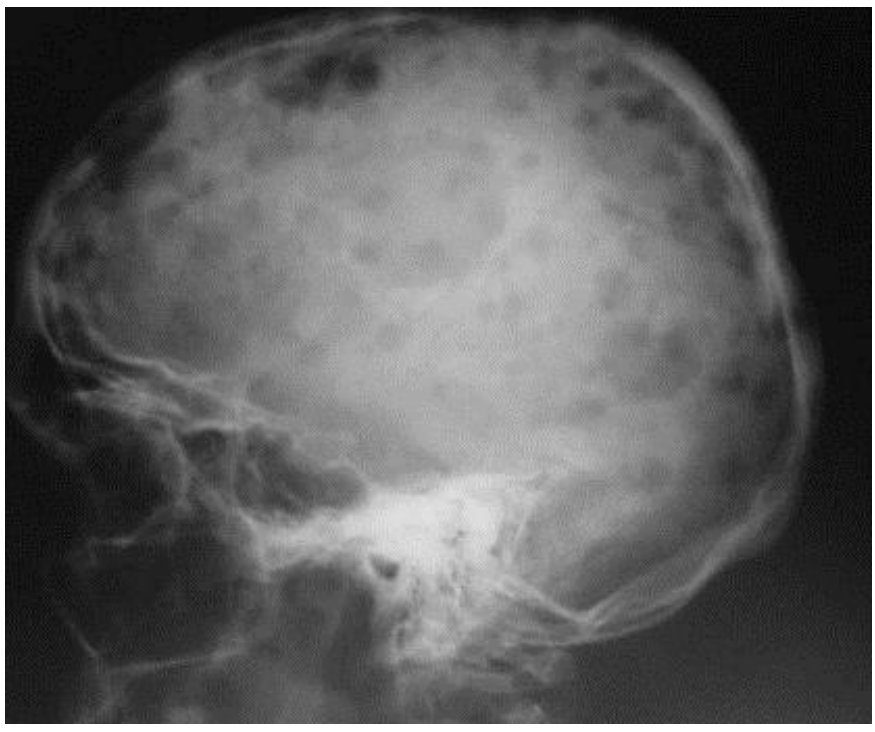

FIGURE 1. Radiography of the skull: osteolytic skull lesions

After a short recovery period, the patient continued the polichemotherapy and underwent preparation for the second autotransplantation, which was performed in July 2016 following a more intensive chemotherapy with busulfan + melphan. The second transplant was well tolerated with a relatively quick recovery of the cell lines, with the disappearance of bone pain and improvement of the paraparesis. The maintenance treatment is carried out with $1.3 \mathrm{mg} / \mathrm{m}^{2}$ subcutaneous bortezomib at 14 days.

The patient agreed to the publication of his data, and the institution where the patient had been admitted approved the publication of the case.

\section{DISCUSSIONS}

We decided to present this case due to its complexity and multidisciplinary character.

In order to solve such a difficult case, an efficient collaboration between the radiologist, the nuclear medicine specialist and the neurosurgeons was needed.

These patients require a very thorough multidisciplinary follow-up in order to be able to detect the relapse in time and to take the necessary methods for a correct and efficient treatment.

Double autologous transplant in young patients with multiple myeloma is a feasible and efficient method of treatment in spite of its aggressiveness.

Maintenance treatment after an autologous stem cell transplantation is a problem that is not completely clarified, ${ }^{5}$ and it can be carried out with bortezomib or thalidomide or lenalidomide. In our case, we initiated maintenance with bortezomib. 
Another important problem is represented by the treatment of these patients in case of relapse after the second autologous transplantation. We consider that in case a relapse occurs, we should be prepared to perform an allogeneic transplantation using a compatible related or unrelated donor, ${ }^{6}$ similarly to the case we presented.

Allogeneic stem cell transplantation comprises many difficulties and complications; however, it is the only treatment that can save these young patients in case of relapse after double autologous transplantation.

\section{CONCLUSIONS}

Multiple myeloma in young patients is a very complex disease that unfortunately has become quite frequent at this age. The complex treatment includes chemotherapy, radiotherapy, and, if necessary, orthopedic or neurosurgical interventions and autologous and/or allogeneic stem cell transplantation.

\section{CONFLICT OF INTEREST}

Nothing to declare.

\section{REFERENCES}

1. Attal M, Harouseau JL, Leyvraz S, et al. Maintenance therapy with thalidomide imporves survival in patinets with multiple myeloma. Blood 2006;108:3289-3294.

2. Barlogie B, Kyle RA, Anderson KC, et al. Standard chemotherapy compared with high dose chemotherapy for multiple myeloma: Final results of a phase III US intergroup trail S9321. J Clin Oncol. 2006;24:929-936.

3. van Rhee F, Giralt S, Barlogie B. The future of autologous stem cell transplantation in myeloma. Blood. 2014;124:328-333.

4. Koreth J, Clutler CS, Djulbegovic B, et al. High-dose therapy with single autologous transplantation versus chemotherapy for newly diagnosed multiple myeloma. A systematic review and meta-analysis of randomised controlled trials. Biol Blood Marrow Transplant. 2007;13:183-196.

5. Kroger N, Perez-Simon J, Myint H, et al. Influence of timing allogenic stem cell transplantation after dose-redused melphalan/fludarabine condition in multiple myeloma. Biol Blood and Marrow Transplant. 2004;10:698708

6. Moreau P, San Miguel J, Ludwig H. Multiple Myeloma: ESMO Clinical Practice Guidelines for diagnosis, treatment and follow-up. Ann Oncol 2013;24(Suppl6):vi133-137. 